\title{
Role of bilateral internal iliac artery ligation in severe obstetric and gynaecological hemorrhage
}

\author{
Shashi Lata Kabra Maheshwari ${ }^{1}$, Nisha Kumari ${ }^{1}$, Syed N. Ahmad ${ }^{2 *}$
}

\begin{abstract}
${ }^{1}$ Department of Obstetrics and Gynecology, Deen Dayal Upadhyay Hospital, New Delhi, India
${ }^{2}$ Department of Obstetrics and Gynecology, ESIC PGIMSR, New Delhi, India
\end{abstract}

Received: 08 January 2018

Accepted: 03 February 2018

\author{
*Correspondence: \\ Dr. Syed N. Ahmad, \\ E-mail: dr.syednawaz@gmail.com
}

Copyright: (C) the author(s), publisher and licensee Medip Academy. This is an open-access article distributed under the terms of the Creative Commons Attribution Non-Commercial License, which permits unrestricted non-commercial use, distribution, and reproduction in any medium, provided the original work is properly cited.

\begin{abstract}
Background: Massive pelvic haemorrhage is a potentially lethal complication while undergoing obstetric and gynaecological surgery. The objective of this study was to study of role of bilateral internal iliac artery ligation in severe obstetric and gynaecological haemorrhage. It was a prospective interventional study carried out in a multispeciality tertiary care hospital in New Delhi.

Methods: Thirty-five patients (31 obstetric and 4 gynaecological) fulfilling the inclusion criteria over a period of 2 years were included in the study cohort after informed consent. After laparotomy, internal iliac arteries were exposed by incising the peritoneal fold between the infundibulo-pelvic and round ligaments. A number 1 silk suture and rightangled artery forceps were used to tie the internal iliac arteries approximately 1 inch below their origin. The success and complications of the procedure were analysed.

Results: In the present study 31 out of 35 cases underwent BIIAL for obstetrical cause of haemorrhage and rest 4 for gynaecological cause. In 19 out of 31 patients, hysterectomy preceded or followed BILAL depending upon the clinical situation making a uterine salvation rate of $38.7 \%$. The success rate of BIIAL was $67.7 \%$ in 31 obstetric cases. In the 4 gynaecological cases BILAL was done to arrest post-hysterectomy haemorrhage and success rate was $100 \%$. Among 35 patients one patient died of haemorrhagic shock and 4 other died of full blown sepsis and MODS in surgical ICU. No significant procedure related complications were encountered.

Conclusions: BILAL is a very effective procedure to control PPH and pelvic haemorrhage due to other causes and helps save the much precious lives and uteri. This procedure can always be tried where procedures like embolization are unavailable.
\end{abstract}

Keywords: Hemorrhaged, Internal iliac artery, Ligation

\section{INTRODUCTION}

Massive pelvic haemorrhage is a potentially lethal complication while undergoing obstetric and gynaecological surgery. Obstetric haemorrhage remains the leading known cause of maternal mortality worldwide with an estimated annual incidence of 140000 deaths. ${ }^{1}$ Similarly in gynaecological cases haemorrhage can prove life threatening. One of the effective methods of controlling severe pelvic haemorrhage is ligation of both hypogastric or internal iliac arteries (IIAL) as these are the major arterial blood supply to pelvic viscera. The technique of internal iliac (hypogastric) arterial ligation for the purpose of controlling pelvic haemorrhage is more than a century old. ${ }^{2}$ Howard Kelly first pioneered ligation of the internal iliac (hypogastric) artery in 1893 in the treatment of intraoperative bleeding from cervical cancer and later in 1963 this procedure was greatly investigated by Burchell RC. ${ }^{3,2}$ Many investigators fear infertility due to BILAL but the fear is unfound and the procedure may save uterus and help preserve fertility. The American college of Obstetricians and gynaecologist continues to 
advocate the use of bilateral internal iliac artery ligation in the management of intraoperative intractable haemorrhage during pelvic surgery or in cases of obstetric haemorrhage. ${ }^{4}$

The purpose of this study is to review efficacy of BIIAL in women with intractable haemorrhage due to gynaecological and obstetrical causes.

\section{METHODS}

This was a prospective interventional study conducted in a tertiary care hospital in New Delhi India over a period of two years. Thirty-five patients with intractable gynaecological or obstetric haemorrhage fulfilling the inclusion criteria were included in the study after informed consent. Approval was sought from the institutional ethical committee for conduction of this research study. The procedures followed were in accordance with the ethical standards of the responsible committee on human experimentation (institutional) and with the Helsinki Declaration of 1975 and revised in $2008 .^{5}$

Patients with intractable bleeding due to trauma or atonicity during caesarean section, vaginal delivery, during hysterectomy for gynaecological indication or haemo-peritoneum in the postoperative period following obstetric or gynaecological surgery were included in the study. Blood loss estimation was done using calibrated mops and suction apparatus. In obstetric cases BILAL was done as the initial procedure as an attempt to salvage the uterus if systolic blood pressure was more than $100 \mathrm{~mm}$ of $\mathrm{Hg}$ and pulse rate was 140 beats/minute or less. However, if the patient was haemodynamically unstable with a systolic blood pressure of less than $100 \mathrm{~mm}$ of $\mathrm{Hg}$ or pulse rate of more than 140 beats/minute or more, hysterectomy was the initial procedure followed by BILAL.

After laparotomy, peritoneum over the external iliac arteries was incised and dissection was carried out to expose the internal iliac arteries which were ligated with the use of a right-angled artery forceps and number 1 silk suture. The right-angled clamp was passed from the lateral to medial side to avoid injury to the external iliac vein. Before ligating the arteries, femoral pulses were palpated in order to be sure that internal iliac artery only was being ligated and to avoid the inadvertent ischaemia and gangrene of the leg due to external iliac artery ligation. The arteries were ligated almost one inch below the bifurcation of the common iliac vessels to avoid ligation of the posterior division of the internal iliac artery. Two ligatures about $1 \mathrm{~cm}$ apart were applied to the arteries. The success rate and the complications of the procedure were studied.

With reference to previous studies, the success rate of bilateral internal iliac artery ligation was about $90 \%$. With the precision error of estimation $(d)=0.10$ and alpha $=0.05$, a sample size of 35 cases was considered adequate for the study.

\section{Statistical analysis}

Descriptive statistics was analysed with SPSS version 17.0 software. Continuous variables were presented as mean \pm SD while those with a skewed distribution was described as a median (IQR). Categorical variables were expressed as frequencies and percentages. Nominal categorical data between the groups was compared using Chi-squared test or Fisher's exact test as appropriate. A p value less than 0.05 was taken to indicate a significant difference.

\section{RESULTS}

Mean age was in the study cohort was $29.91 \pm 8.86$. Only 20 patients among 35 were booked. Obstetric cases were complicated by certain co-morbid conditions like anaemia, pre-eclampsia, placenta praevia etc.

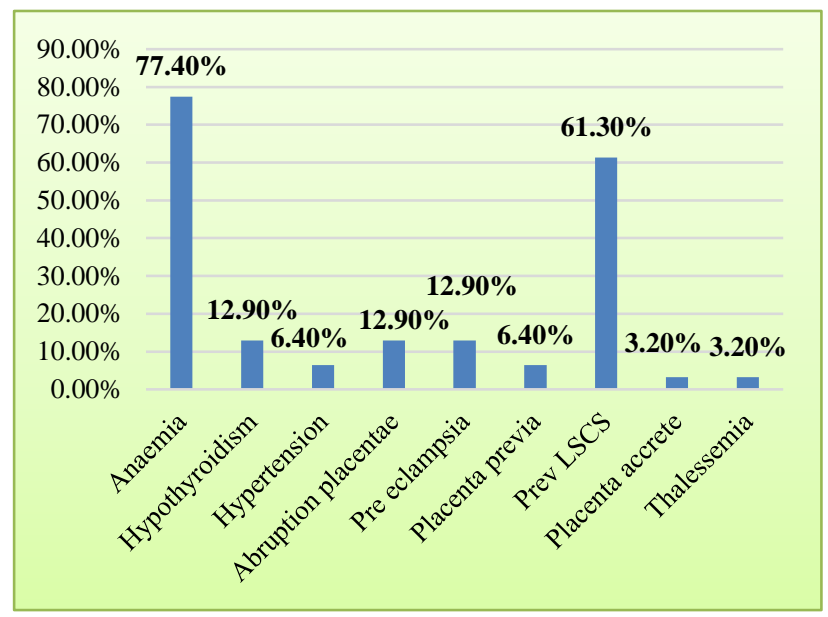

Figure 1: Frequency of distribution of co-morbid conditions in obstetric cases.

Distribution of the co-morbid conditions in the study cohort is depicted in Figure 1 and 2.

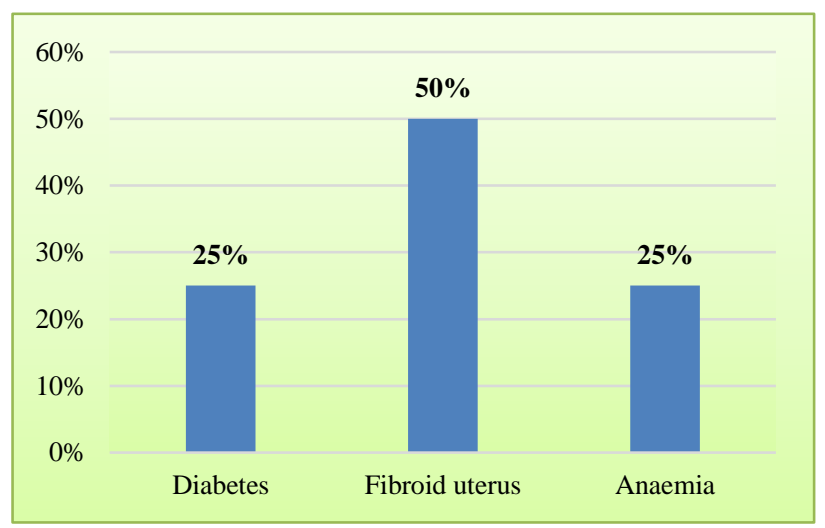

Figure 2: Frequency distribution of co-morbid conditions in gynaecological cases 
Table 1: Frequency distribution of patients as per mode of delivery.

\begin{tabular}{|llll|}
\hline \multirow{4}{*}{ Mode of delivery } & Caesarean section & 15 & 48.4 \\
\cline { 2 - 4 } Abdominal & Hysterotomy & 3 & 9.7 \\
& $\begin{array}{l}\text { Laparotomy for rupture } \\
\text { uterus }\end{array}$ & 3 & 9.7 \\
\hline \multirow{2}{*}{ Total } & & 21 & 67.8 \\
\hline \multirow{2}{*}{ Vaginal } & IUD* vaginal delivery & 3 & 9.7 \\
\cline { 2 - 4 } & Term vaginal delivery & 6 & 19.3 \\
\cline { 2 - 4 } & Preterm vaginal delivery & 1 & 3.2 \\
\hline Total & 10 & 32.2 \\
\hline
\end{tabular}

Mode of delivery in the obstetric group is depicted in Table 1. Commonest primary surgery in obstetric cases was caesarean section (Figure 3). Twenty-two (62.9\%) patients had blood loss more than 2.5 litres with a mean of 2.39 \pm 0.40 litres. Commonest indication for BILAL was atonic PPH $12(34.3 \%)$ followed by post-obstetric hysterectomy haemorrhage $9(25.7 \%)$.

Other indications of BILAL are summarized in Table 2. In $20(57.1 \%)$ patients BIIAL was done at the time of primary surgery while as in the rest it was done within 124 hours of the primary surgical procedure.

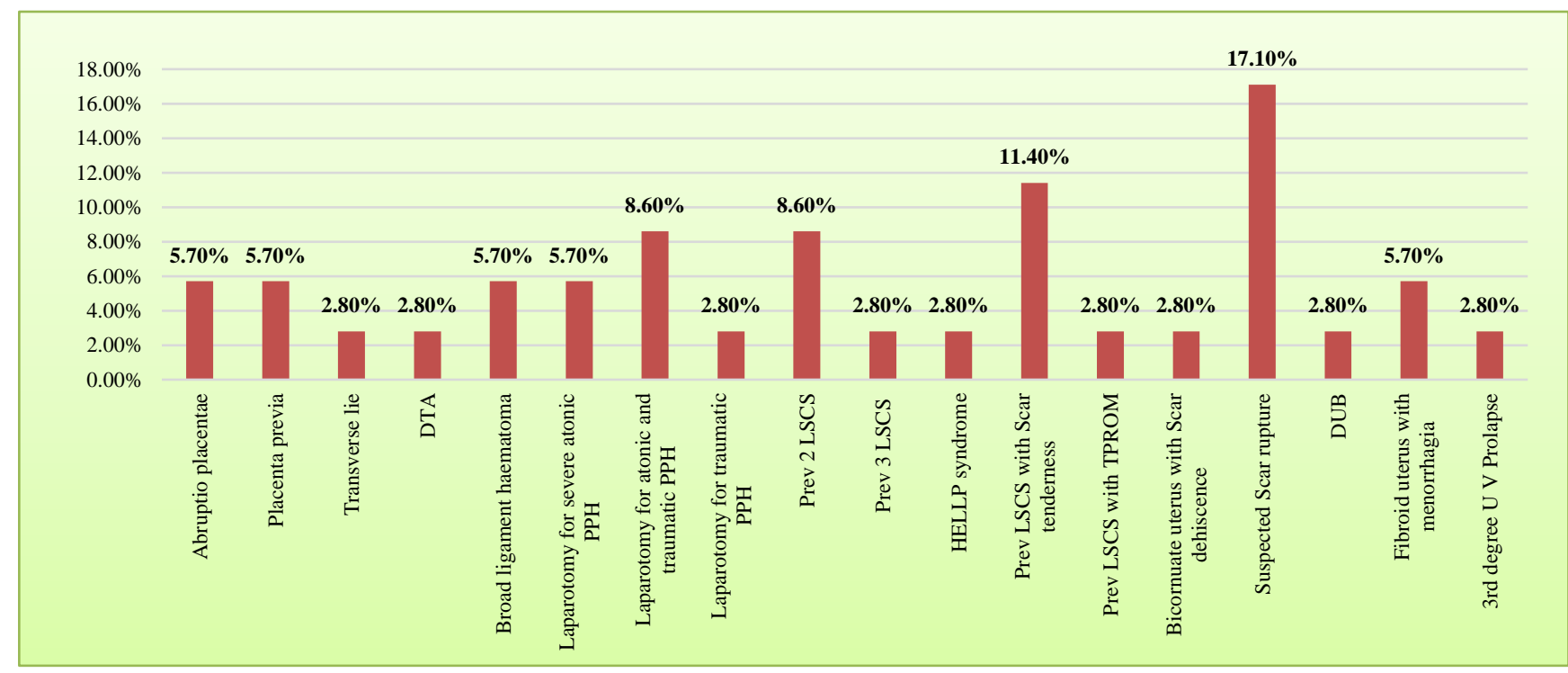

Figure 3: Distribution of patients as per indication of primary surgery.

In $22(62.9 \%)$ obstetric patients BILAL was done before hysterectomy, however in 10 of these patients' haemostasis couldn't be achieved and hysterectomy was done. In $13(37.1 \%)$ patients BILAL followed hysterectomy and was successful in controlling bleeding. The cumulative success of BILAL in achieving haemostasis was $71.4 \%$. The uterine salvage rate in the 22obstetric cases where BILAL preceded hysterectomy was $54.5 \%$.

Table 2: Indications of bilateral internal iliac artery ligation.

\begin{tabular}{|c|c|c|c|c|}
\hline Indication & & Indication of BIIAL & Frequency & Percentage \\
\hline \multirow{7}{*}{ Obstetric } & Atonic PPH & Atonic PPH & 12 & 34.3 \\
\hline & \multirow{5}{*}{ Traumatic PPH } & Broad ligament haematoma & 2 & 5.7 \\
\hline & & Vault tear & 1 & 2.8 \\
\hline & & Torn uterine arteries & 4 & 11.4 \\
\hline & & Scar rupture extending to cervix & 2 & 5.7 \\
\hline & & Uterine angle extension till vagina & 1 & 2.8 \\
\hline & Post-operative haemorrhage & $\begin{array}{l}\text { Post-obstetric hysterectomy } \\
\text { haemorrhage }\end{array}$ & 9 & 25.7 \\
\hline Gynaecological & Post-operative haemorrhage & Post-hysterectomy haemorrhage & 4 & 11.4 \\
\hline Total & & & 35 & 100 \\
\hline
\end{tabular}


There were no procedure related complications. Out of 35 patients $29(82.9 \%)$ required ICU admission. One patient died of haemorrhagic shock and four other patients died of sepsis in the intensive care unit. Average duration of hospital stay was 12 days.

\section{DISCUSSION}

Bilateral internal iliac artery ligation is an effective lifesaving method to control obstetrical and gynaecological haemorrhage and a hysterectomy can often be avoided. Previously in severe obstetric haemorrhage the traditional surgical treatment was to perform an emergency hysterectomy thus eliminating the possibility of future fertility. But BIIAL has emerged in an alternative lifesaving procedure with the advantage of preserving future fertility in addition to less operative time, lesser cost, less chances of operative complications like bladder injury and post-operative adhesion formation. BILAL was under-utilized previously probably due to lack of expertise in performing the procedure. But with the advances in the surgical skill and better knowledge of retroperitoneum, internal iliac artery ligation is gaining a foothold in many centres. The main indications for which the procedures are practiced remain more or less the same as our study. ${ }^{5,6}$ We used a right-angled clamp for the procedure as have many other authors. ${ }^{7,8}$

In the present study we used silk suture for the ligation of internal iliac although many surgeons use polyglycolic acid suture as well. ${ }^{9}$ We found BILAL as a very good modality for atonic as well as traumatic PPH especially when the uterine arteries had retracted and couldn't be ligated and lead to haematoma formation in cervical and vaginal lacerations where uterine artery ligation wasn't very effective because of additional supplies from the descending cervical and vaginal arteries, internal iliac ligation was found very successful. In cases of morbid placentation as accreta and percreta, although uterine artery embolization is an option but the limited availability of this facility in addition to the procedure related complications like bladder and uterine necrosis, fever and sepsis limits its use. ${ }^{10-12}$ Although, internal iliac vein injury is a well-recognised complication of internal iliac artery because of the anatomical location of the former being just underneath the latter, we didn't encounter this complication. ${ }^{7}$ BILAL proved very efficacious in post-hysterectomy gynaecological cases as well.

\section{CONCLUSION}

BILAL is a life-saving procedure when the more advanced methods like embolization are unavailable. Although it needs surgical expertise, the procedure can be learned quickly with a good knowledge of the pelvic anatomy. It helps to preserve the future fertility and hence no patient should be denied the procedure shall the circumstances and clinical condition of the patient permit.

Funding: No funding sources

Conflict of interest: None declared

Ethical approval: The study was approved by the Institutional Ethics Committee

\section{REFERENCES}

1. Abouzahn C. Global burden of maternal death and disability. Br Med Bull. 2003;67:1-11.

2. Burchell RC. Physiology of internal iliac artery ligation. J Obstet Gynaecol $\mathrm{Br}$ Common. 1968;72:642-51.

3. Kelly HA. Ligation of internal iliac arteries for haemorrhage in hysterectomy for carcinoma uteri. Bull Johns Hopkins Hosp. 1894;5:53.

4. American college of obstetrician and gynecologist. Haemorrhagic shock. ACOG Educational Bull. $1997 ; 235$.

5. Camuzcuoglu H, Toy H, Vural M, Yildiz F, Aydin H J Obstet Gynaecol Res. 2010; 36(3):538-43.

6. Mandal D, Mandal S, Maity TK, Parmanik S, Biswas SC. Role of hypogastric artery ligation in pelvic hemorrhage is still alive. Al Ameen J Med Sci. 2013;6(1).

7. Evsen MS, Sak ME, Soydinc HE, Basaranoglu S, Bakir C, Sak S, et al. Internal iliac artery ligation for severe postpartum hemorrhage. Ginekol Pol. 2012;83:665-8.

8. Joshi VM, Otiv SR, Majumder R, Nikam YA, Shrivastava M. Internal iliac artery ligation for arresting postpartum hemorrhage. BJOG. 2007;114:356-61.

9. Singh A, Kishore R, Saxena SS. Ligating internal iliac artery: success beyond hesitation. J Obstet Gynecol India. 2016;66(1):235-41.

10. Porcu G, Roger V, Jacquier A, Mazouni C, RojatHabib MC, Girard G, et al. Uterus and bladder necrosis after uterine artery embolization for postpartum haemorrhage. BJOG. 2005;112:122

11. Cottier JP, Fignon A. Uterine necrosis after arterial embolization for postpartum haemorrhage. Obstet Gnecol. 2002;100:1074-7.

12. Hare W, Holland CJ. Paresis following internal iliac artery embolization. Radiol. 1983;146:47-51.

Cite this article as: Maheshwari SLK, Kumari N, Ahmad SN. Role of bilateral internal iliac artery ligation in severe obstetric and gynaecological hemorrhage. Int J Reprod Contracept Obstet Gynecol 2018;7:1090-3. 